\title{
Flight muscle breakdown in the green-veined white butterfly, Pieris napi (Lepidoptera: Pieridae)
}

\author{
FREDRIK STJERNHOLM and BENGt KARLSSON*
}

Department of Zoology, Stockholm University, S-106 91 Stockholm, Sweden

Key words. Pieridae, Pieris napi, flight performance, life history, reproduction

\begin{abstract}
Flight is important for insects but also incurs costs in terms of reduced reproductive reserves. Recent studies on butterflies have shown that thorax mass and nitrogen content decrease over the adult lifespan, suggesting that flight muscle breakdown may also occur in butterflies. However, unlike other insects known to resorb flight muscles, butterflies will continue to fly throughout the reproductive period. Nonetheless, use of nutrients from flight muscles for reproduction has the potential to improve the reproductive output considerably. In this study we have tested to what extent female Pieris napi L. (Pieridae) butterflies actually do breakdown flight muscles. By comparing muscle mass in recently emerged and older free-flying females we show that mass and nitrogen content of the two most important groups of flight muscles each decrease by more than $50 \%$ over the adult lifespan. The significance of this finding is discussed in relation to reproduction and flight in butterflies.
\end{abstract}

\section{INTRODUCTION}

Flight is important for most insects. It increases the range over which food, partners and suitable habitat for breeding can be found, and in some species flight is a prerequisite for long distance migration. Flight is also used by many species for evading predators, courtship and male-male contests.

Nonetheless, in some insects the potential benefits of flight are counterbalanced by the cost of the flight apparatus, and flight ability has been lost (Roff, 1986, 1990; Sattler, 1991; Zera \& Denno, 1997). In situations where resources are scarce and/or flight is of marginal importance fitness may be higher if resources are used directly for reproduction than if they are used to build, maintain and fuel the flight apparatus (Roff, 1986; Zera \& Denno, 1997). Sandlan (1979) presented circumstantial evidence for flight muscle degeneration in starved adults of the parasitoid wasp Coccygomimus turionellae; flight capability decreased but egg production could continue.

The costs of flight have predominantly been studied in flight polymorphic species where the flightless morph usually has higher fecundity and/or earlier sexual maturity compared to the flight capable morph. Interestingly, the respective benefits of flight ability and flightlessness need not be mutually exclusive. In several insect orders females and in some cases also males emerge as adults with fully developed flight muscles that may subsequently degenerate before or during the reproductive stage (Johnson, 1976; Zera \& Denno, 1997; Marden, 2000). This strategy is usually practised in species that, after a migratory or dispersal phase in early adult life, settle down to reproduce (Johnson, 1969; Harrison, 1980). In some species muscle breakdown may also occur without prior flight/dispersal (e.g. Edwards, 1969; Sol- breck, 1986; Kaitala \& Hulden, 1990), if local conditions are favourable for reproduction. Similar to the fecundity benefit realised by flightless individuals in flightpolymorphic species, muscle breakdown has been shown to increase fecundity in comparison to individuals that retain their flight muscles (e.g. Kaitala, 1988; Kaitala \& Hulden, 1990; Tanaka \& Suzuki, 1998), thus this life style provides many of the benefits of flight, while not incurring all the costs.

The possibility for flight muscle breakdown in insects with a lifelong dependence on flight is less obvious. Nonetheless, recent studies on butterflies suggest this possibility, as both thorax mass and nitrogen content decrease over the adult lifespan in many species (Karlsson, 1994, 1998; Stjernholm \& Karlsson, 2000; Norberg \& Leimar, 2002, Stjernholm et al., 2005). Furthermore, in Pieris napi resources stored in the abdomen together with resources obtained from nuptial gifts do not suffice to explain egg production. In order to balance the nitrogen (protein) budget, resources from the thorax, possibly from flight muscles, have to be included (Karlsson, 1998). Even though butterflies, with few exceptions, are strongly dependent on flight, the low quality of the adult diet in many species suggests that reallocation of muscle resources to reproduction could increase fitness. Since in butterflies, abdomen mass decrease with age, relative muscle mass would decrease more slowly than absolute muscle mass and this could keep the negative impact on flight ability at a low level. This would shift the costbenefit balance and facilitate muscle breakdown, but whether muscles actually degenerate over the lifespan of butterflies is not known.

The aim of this paper is to test whether, and to what extent, butterflies actually do breakdown flight muscles during the course of life. We do this by comparing flight

\footnotetext{
* Corresponding author; e-mail: bengt.karlsson@zoologi.su.se
} 
muscle mass and nitrogen content in recently emerged $P$. napi females with the mass and nitrogen content of the muscles at death in free-flying females with a long lifespan.

\section{MATERIAL AND METHODS}

The animals for this study were the offspring of four females caught in the vicinity of Stockholm, Sweden. The offspring of these four females (families) were reared in a common environment on garlic mustard (Alliaria petiolata) in groups of three in $1.0 \mathrm{~L}$ plastic jars. The temperature during the larval stage was $20^{\circ} \mathrm{C}$ and a $22 \mathrm{~L}: 2 \mathrm{D}$ regime, which prevents diapause. At eclosion the adults were sexed and weighed to the nearest $0.5 \mathrm{mg}$ once they had released the meconial wastes and become active. The females were then divided into two treatments. The first treatment consisted of 10 females that were frozen directly at the start of the experiment. The females in the second treatment were kept flying in two $0.5 \mathrm{~m}^{3}$ indoor cages, with ten females in each cage. These females were fed $20 \%$ sugar solution ad libitum and were provided with garlic mustard leaves on which to oviposit. During the experiment the regime was 9L: 15D. Since the number of matings is known to affect the decrease in thorax nitrogen content in this species, either directly or indirectly via an increase in lifespan (Karlsson, 1998), the females were provided with a continuous supply of virgin males throughout the experiment so that the sex ratio was approximately $1: 1$. After each mating the male was removed from the cage and replaced with a virgin male. After natural death, the females were frozen. The experiment terminated when all females had died. Average adult lifespan among these females was $20.0 \pm 1.2$ days (mean \pm S.E), which seems to be close to the maximum lifespan in this species (Wiklund et al., 1993; Karlsson, 1998). Thus, since the degree of muscle breakdown should be age dependent, the results give an estimate of the degree of breakdown possible.

In order to determine the mass of the flight muscles in the two treatments, the indirect dorso-longitudinal flight muscles in the mesothorax (DLM) and the indirect dorso-ventral flight muscles in the meso- and metathorax (DVM), were dissected out of the butterflies in a semi-dry state. Following the numbering of Ehrlich \& Davidson (1961) and Ehrlich \& Ehrlich (1963), the DLM muscles are \#50-54, the DVM muscles are \#56-60 (mesothorax), and \#88-91 (metathorax). The muscles were dried to constant weight at $60^{\circ} \mathrm{C}$ and weighed on a Cahn C-30 microbalance (accuracy $1 \mu \mathrm{g}$ ). Since a change in muscle proteins may be the most important factor from a reproductive perspective, the nitrogen content of the muscles was measured using a Carlo Erba NA 1400 elemental analyser. Data were analysed using ANCOVA; GLM, program STATISTICA 5.5 (StatSoft, 1999). To investigate if there exists a proportional change between two variables, we tested if the slope (b) in the logarithmic transformed equation, $\log \mathrm{y}=\mathrm{b} \log \mathrm{x}+\log \mathrm{a}$, differed from 1 . If the slope is equal to 1 , then the $\mathrm{x} / \mathrm{y}$ ratio is unaffected by a change in $\mathrm{x}$.

\section{RESULTS}

There was no difference in eclosion body mass between the two treatments (eclosion mass for females killed at the start of the experiment $58.7 \pm 1.4 \mathrm{mg}$, free-flying females $59.4 .2 \pm 1.2 \mathrm{mg}$ (mean \pm S.E), ANOVA $\mathrm{F}_{1,26}=0.147, \mathrm{p}=$ 0.70). In the group of females frozen at the start of the experiment the DLMs contained $189 \pm 13.1 \mu \mathrm{g}$ nitrogen and the DVMs $134 \pm 10.2 \mu \mathrm{g}$ nitrogen (mean \pm S.E). The amount of nitrogen remaining in the flight muscles at
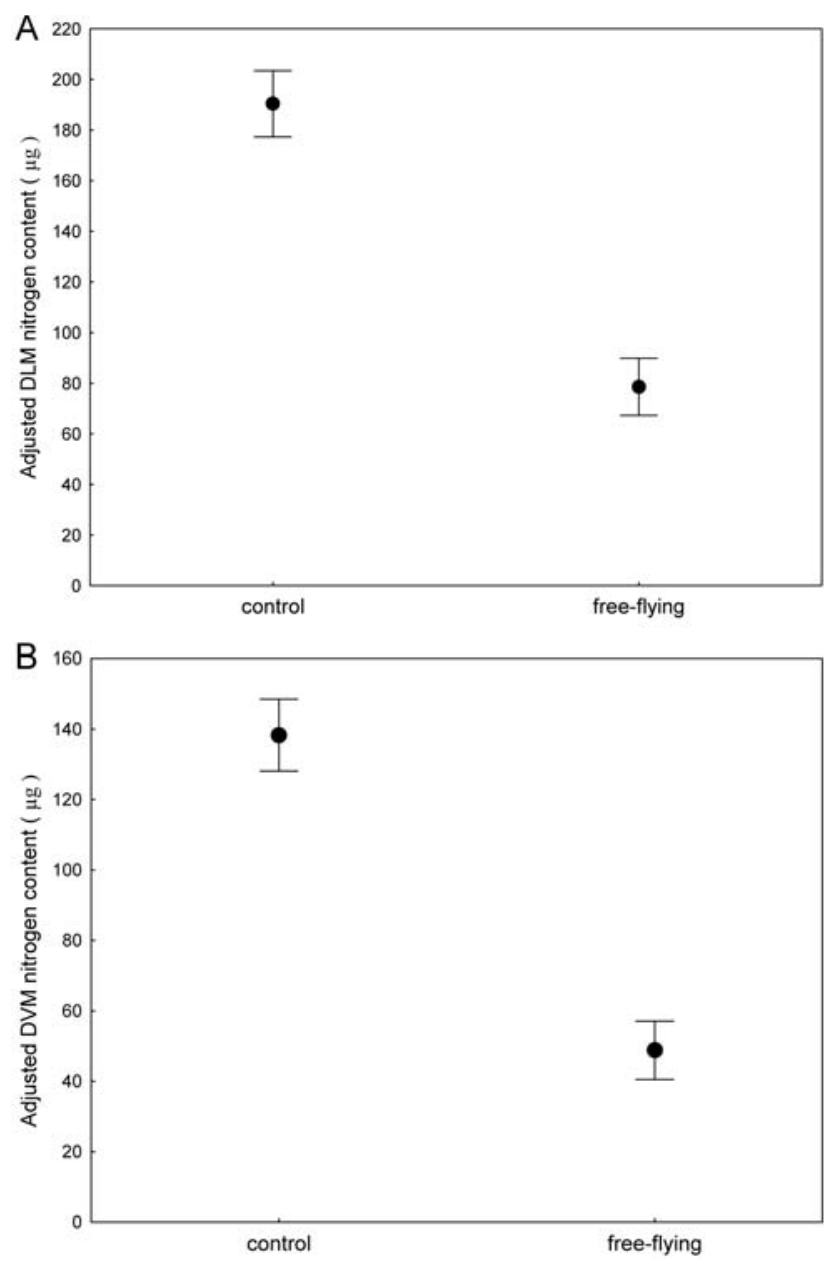

Fig. 1. Nitrogen content of flight muscles in newly emerged (control) and free-flying $P$. napi females (mean \pm S.E.). A values for the mesothoracic dorsolongitudinal flight muscles (DLM); B - values for the meso- and metathoracic dorsoventral flight muscles (DVM). Values are adjusted for differences in eclosion mass.

death in free-flying females was $80 \pm 11.3 \mu \mathrm{g}$ in the DLMs and $52 \pm 8.3 \mu \mathrm{g}$ in the DVMs (mean \pm S.E), equivalent to $42 \%$ (DLM) and 39\% (DVM) of the levels in the females frozen at the start of the experiment. The difference in nitrogen content between the two treatments was highly significant for both muscle groups, DLMs $F_{1,19}$ $=53.6, \mathrm{p}<0.001$ (Fig. 1a), DVMs $F_{1,16}=57.3, \mathrm{p}<0.001$ (Fig. 1b), (ANCOVA with eclosion mass as covariate and with family as random factor). There was no effect of family in any of the muscle groups regarding remaining nitrogen at death (DLM: $\mathrm{F}_{3,19}=1.41, \mathrm{p}=0.269$; DVM: $\left.\mathrm{F}_{3,16}=0.43, \mathrm{p}=0.735\right)$.

In the free-flying group of females both nitrogen DLMs and nitrogen DVMs showed a significant negative relationship with life span (Fig. 2). There was no effect of family on remaining nitrogen in DLM or DVM $\left(\mathrm{F}_{3,11}=\right.$ $0.330, \mathrm{p}=0.804 ; \mathrm{F}_{3,10}=0.251, \mathrm{p}=0.859$ respectively). The females had mated $1.8 \pm 0.16$ times (mean \pm S.E) and number of matings correlated with life $\operatorname{span}(\mathrm{r}=0.55, \mathrm{p}=$ $0.028)$. 

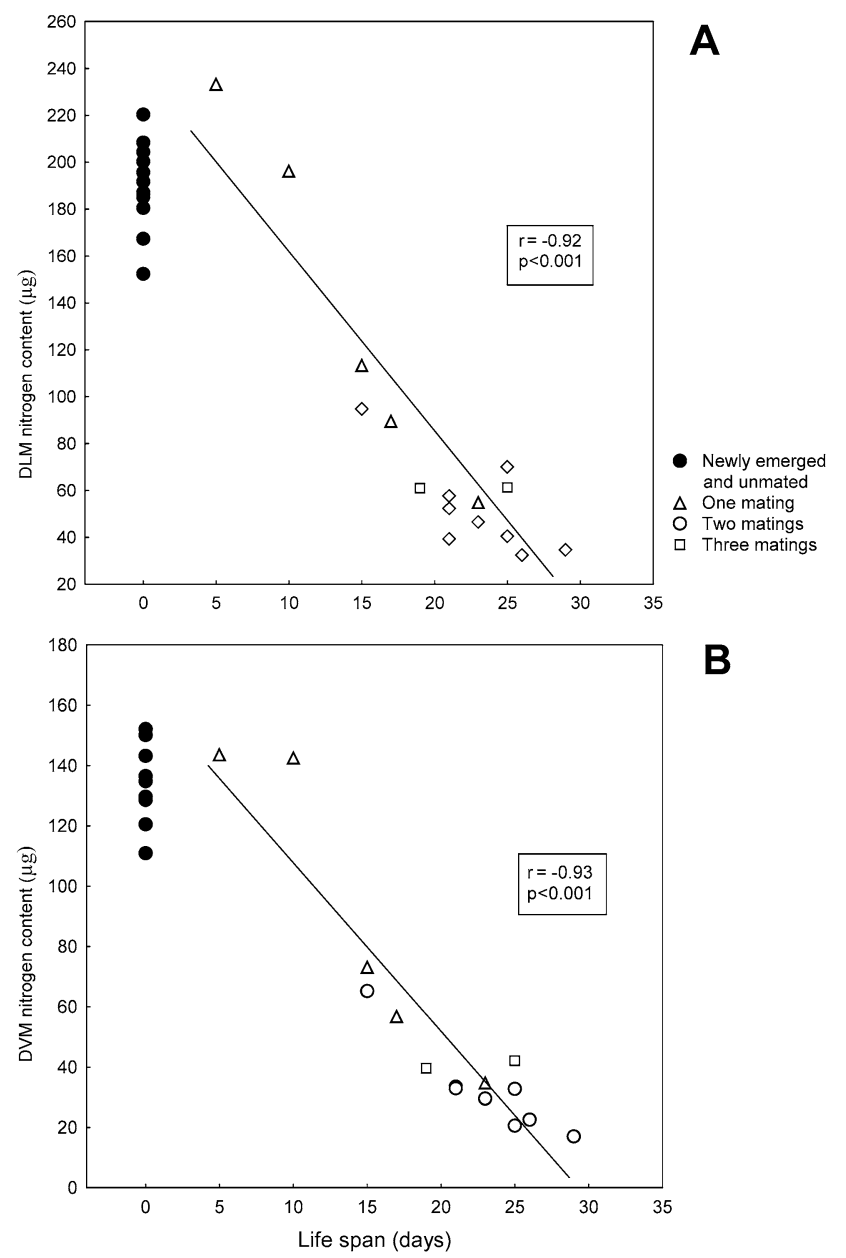

B

Fig 2. Relationship between life span and muscle nitrogen content. A - values for the mesothoracic dorsolongitudinal flight muscles (DLM); B - values for the meso- and metathoracic dorsoventral flight muscles (DVM). Filled circles represent values for newly emerged and unmated females (control) and are not included in the presented regression lines.

For both DLMs and DVMs there was a close relationship between muscle mass and nitrogen content. For the DLMs the relationship between muscle mass and nitrogen content was highly significant $(\mathrm{r}=0.999, \mathrm{p}<0.0001)$, although the slope of the logarithmic equation was significantly non-isometric $(b>1)$, but the deviation was small, $\mathrm{b}=1.02, \mathrm{t}_{(26)}=3.90, \mathrm{p}<0.001$. For the DVMs the relationship was again highly significant $(r=0.999, p<$ 0.0001 ) but the slope of the logarithmic equation was not significantly different from $1, \mathrm{~b}=1.01, \mathrm{t}_{(23)}=1.67, \mathrm{NS}$. Thus it seems that the decrease in nitrogen content is a result of decrease in muscle size and not a change in nitrogen content per unit muscle.

\section{DISCUSSION AND CONCLUSIONS}

Flight muscle breakdown has been hypothesised to occur in butterflies, since thorax mass and nitrogen content decrease with age in many species (Karlsson, 1994, 1998; Stjernholm \& Karlsson, 2000; Norberg \& Leimar, 2002; Stjernholm et al., 2005). We tested this prediction for the first time. The comparison of flight muscle size in recently emerged and older free-flying $P$. napi females demonstrated that the mass and nitrogen content of the two major groups of flight muscles in long-lived females is less than $42 \%$ of the levels in recently emerged females, confirming that much of the musculature is broken down over the lifespan. Flight muscle breakdown has previously been recorded in insects of several orders (Johnson, 1976; Sandlan, 1979; Zera \& Denno, 1997; Marden, 2000), but has up till now only been found in association with a lifestyle where flight primarily is important before but not during the reproductive period. Thus, this study explicitly shows that the flight muscles can be broken down to a large extent in an insect that is strongly dependent on flight over the entire lifespan.

It is likely that flight muscle breakdown also occurs in other butterfly species, since for females under natural conditions, thorax mass decreases over the adult lifespan in most of the species that have been studied (Karlsson, 1994; Norberg \& Leimar, 2002; Stjernholm et al., 2005), and the decrease is generally of roughly the same magnitude as in P. napi (Stjernholm et al., 2005). Thorax mass also decreases in males of some species but generally to a lesser extent (Karlsson, 1994; Norberg \& Leimar, 2002; Stjernholm et al., 2005). This suggests that flight muscle breakdown is a general phenomenon in butterflies, particularly in females, where the decrease in thorax mass is most pronounced. The relationship between muscle mass and nitrogen content suggests that the decrease in nitrogen content results from whole scale breakdown of muscles, rather than special mobilisation of muscle nitrogen.

Since reproductive potential in female butterflies seems to be determined by the availability of essential amino acids for egg production (Boggs, 1981; O'Brien et al., 2002), selective degeneration of flight muscles could conceivably increase fitness by contributing to the pool of resources available for reproduction. This is supported from work on resource use by $P$. napi females, which shows that nitrogenous resources from the thorax are used for egg production (Karlsson, 1998).

With the results in this study we can now be quite sure that resources in the thorax used for egg production originate from nutrients in the flight muscles. It is less likely that resorbed flight muscle resources are allocated for somatic maintenance (cf. Karlsson, 1998). Also in P. napi males are thorax resources used for reproduction (Stjernholm \& Karlsson, 2006).

Reallocation of muscle resources (amino acids) to reproduction in males could also be important in species that invest large quantities of proteins in spermatophores, and recent studies indicate that the reduction in thorax mass and nitrogen content increases with the reproductive investment both inter- and intra-specifically (Stjernholm et al., 2005; Stjernholm \& Karlsson, 2006). Since number of matings increases life span in P. napi (Karlsson, 1998) it may be that the full potential of wing muscle breakdown is only achieved when females have the opportunity of multiple matings (cf. Fig. 2). 
Breakdown of muscles may also have a negative impact on fitness through deterioration in flight performance. A reduction in flight speed, manoeuvrability and/or endurance may increase the risk of predation and could also reduce the ability to find food, host plants or partners. Flight performance is determined by energy availability and flight morphology, e.g. wing shape, wing loading and relative flight muscle size (Marden, 2000; Berwaerts et al., 2002). Relative flight muscle size (FMR) has often been used as a relevant factor when examining flight performance (e.g. Marden \& Chai, 1991; Berwaerts et al., 2002). Studies investigating the change in FMR or relative thorax size over the lifespan in butterflies have found little support for a substantial decrease in relative flight muscle size (Kemp, 2002; Stjernholm et al., 2005). In females of $P$. napi relative thorax mass is roughly similar between young and old females (Stjernholm et al., 2005). This result may be a consequence of body resources other than flight muscles being used for metabolism and egg production at a rate similar to or higher than the rate of flight muscle breakdown, and even though the change in relative thorax mass may underestimate the change in FMR, it suggests that the cost of flight muscle breakdown in butterflies may be relatively small, thereby facilitating the evolution of flight muscle breakdown. Since egg (and spermatophore) production is highest early in life (Stern \& Smith, 1960; Labine, 1968; Wiklund et al., 1993; O'Brien et al., 2004), while muscle breakdown seems to occur at a more constant rate, when judged by the change in thorax mass (Karlsson, 1998; Stjernholm et al., 2005), it may be the case that flight performance increases initially only to deteriorate late in a butterfly's life. Presently the dynamics of how flight performance changes with flight muscle breakdown and age are largely unknown and further research is warranted to establish the nature of the relationship.

The results of this study also raise the question of how common flight muscle breakdown is in other insects that are dependent on flight throughout their life. Assuming that resources from the flight muscles are used for reproduction, muscle breakdown should be found in association with low quality adult diets and/or large investment of resources in egg or ejaculate/spermatophore production. The diet could be of low quality either by having low nitrogen content or being nutritionally balanced but available in low or unpredictable quantities. As in butterflies, it seems that the greatest potential to find flight muscle breakdown should be in females, which generally seem to invest more resources in reproduction than males do.

To summarise, this study shows that substantial flight muscle breakdown occurs in $P$. napi females. Even though the generality and functional consequences of this finding are largely unknown, previous studies suggest that this have important consequences for the availability of valuable resources and thus increase the reproductive potential.

Muscle breakdown may also affect flight performance, particularly late in life, with consequences for dispersal, sexual contests and susceptibility to predation. From this perspective flight muscle breakdown in butterflies may have important consequences for various components of the life history strategy, but to understand the ramifications of muscle breakdown will require further studies.

ACKNOWLEDGMENTS. We thank B. Borg, C. Boggs, K. Fischer, M. Jervis and C. Wiklund for kindly commenting on the manuscript. This work was supported by a grant from Alice and Lars Siléns foundation.

\section{REFERENCES}

Berwaerts K., van Dyck H. \& Aerts P. 2002: Does flight morphology relates to flight performance? An experimental test with the butterfly Pararge aegeria. Funct. Ecol. 16: 484-491.

Boggs C.L. 1981: Nutritional and life-history determinants of resource allocation in holometabolus insects. Am. Nat. 117: 692-709.

EDWARDS F.J. 1969: Environmental control of flight muscle histolysis in the bug Dysdercus intermedius. J. Insect Physiol. 15: 2013-2020.

EhrLich P.R. \& DAVIDSON S.E. 1961: The internal anatomy of the monarch butterfly, Danaus plexippus L. (Lepidoptera: Nymphalidae). Microentomology 24: 87-133.

EhrLich P.R. \& Ehrlich A.H. 1963: The thoracic and basal abdominal musculature of the butterflies (Lepidoptera: Papilionoidea). Microentomology 25: 91-126

Harrison R.G. 1980: Dispersal polymorphism in insects. Annu. Rev. Ecol. Syst. 11: 95-118.

JoHnson C.G. 1969: Migration and Dispersal of Insects by Flight. Methuen, London, xxii +766 pp.

JoHNSON C.G. 1976: Lability of the flight system: a context for functional adaptation. In Rainey R.C. (ed.): Insect Flight. Blackwell, London, pp. 217-234.

Kaitala A. 1988: Wing muscle dimorphism: two reproductive pathways of the waterstrider Gerris thoracicus in relation to habitat instability. Oikos 53: 222-228.

KaitALA A. \& HuldÉn L. 1990: Significance of spring migration and flexibility in flight-muscle histolysis in waterstriders (Heteroptera, Gerridae). Ecol. Entomol. 15: 409-418.

KARLSSON B. 1994: Feeding habits and change of body composition with age in three nymphalid butterfly species. Oikos 69: 224-230.

KARLSSON B. 1998: Nuptial gifts, resource budgets and reproductive output in a polyandrous butterfly. Ecology 79: 2931-2940.

KEMP D.J. 2002: Butterfly contest and flight physiology: why do old males fight harder? Behav. Ecol. 13: 456-461.

LABINE P.A. 1968: The population biology of the butterfly, Euphydryas editha. VIII. Oviposition and its relation to patterns of oviposition in other butterflies. Evolution 22: 799-805.

MARDEN J.H. 2000: Variability in the size, composition and function of insect flight muscles. Annu. Rev. Physiol. 62: $157-178$.

Marden J.H. \& Chai P. 1991: Aerial predation and butterfly design: how palatability, mimicry, and the need for evasive flight constrain mass allocation. Am. Nat. 138: 15-36.

Norberg U. \& LeIMAR O. 2002: Spatial and temporal variation in flight morphology in the butterfly Melitaea cinxia (Lepidoptera: Nymphalidae). Biol. J. Linn. Soc. 77: 445-453.

O'Brien D.M., Fogel M.L. \& Boggs C.L. 2002: Renewable and non renewable resources: amino acid turnover and allocation to reproduction in Lepidoptera. Proc. Nat. Acad. Sci. USA 99: 4413-4418. 
O’Brien D.M., Boggs C.L. \& Fogel M.L. 2004: Making eggs from nectar: the role of life history and dietary carbon turnover in butterfly reproductive resource allocation. Oikos 105: 279-291.

RofF D.A. 1986: The evolution of wing dimorphism in insects. Evolution 40: 1009-1020.

RoFF D.A. 1990: The evolution of flightlessness in insects. Ecol. Monogr. 60: 389-421.

SandLan K.P. 1979: Host-feeding and its effects on the physiology and behaviour of the ichneumonid parasitoid, Coccygomimus turionellae. Physiol. Entomol. 4: 383-392.

SATtLER K. 1991: A review of wing reduction in Lepidoptera. Bull. Br. Mus. Nat. Hist. (Entomol.) 60: 243-288.

SOLBRECK C. 1986: Wing and flight muscle polymorphism in a lygaeid bug, Horvathiolus gibbicollis: determinants and life history consequences. Ecol. Entomol. 11: 435-444.

StatSoft Inc. 1999: STATISTICA for Windows [Computer program manual]. Tulsa, OK: StatSoft, Inc., 2300 East 14th Street, Tulsa, OK 74104, WEB: http://www.statsoft.com

STERN V.M. \& SMith R.F. 1960: Factors affecting egg production and oviposition in populations of Colias philodice eurytheme Boisduval (Lepidoptera: Pieridae). Hilgardia 29: 411-454.
StJernholm F. \& Karlsson B. 2000: Nuptial gifts and the use of body resources for reproduction in the green-veined white butterfly Pieris napi. Proc. R. Soc. Lond. (B) 267: 807-811.

StJernholm F., Karlsson B. \& Boggs C.L. 2005: Age-related changes in thoracic mass: possible reallocation of resources to reproduction in butterflies. Biol. J. Linn. Soc. 86: 363-380.

StJERNHOLM F. \& KARLSSON B. 2006: Reproductive expenditure affects utilisation of thoracic and abdominal resources in male Pieris napi males. Funct. Ecol. 20: 442-448.

TANAKA S. \& SuzuKi Y. 1998: Physiological trade-offs between reproduction, flight capability and longevity in a wingdimorphic cricket, Modicogryllus confirmatus. J. Insect Physiol. 44: 121-129.

Wiklund C., Kaitala A., Lindfors V. \& Abenius J. 1993: Polyandry and its effect on female reproduction in the greenveined white butterfly (Pieris napi L.). Behav. Ecol. Sociobiol. 33:25-33.

Zera A.J. \& Denno R.F. 1997: Physiology and ecology of dispersal polymorphism in insects. Annu. Rev. Entomol. 42: 207-230.

Received October 22, 2007; revised and accepted December 4, 2007 